\title{
Drivers for embedding sustainability strategies within the Abu Dhabi public sector organisation: an empirical study
}

\author{
Suresh Renukappa* \\ Faculty of Science and Engineering, \\ University of Wolverhampton, \\ Wolverhampton WV1 1LY, UK \\ Email: suresh.renukappa@wlv.ac.uk \\ *Corresponding author
}

\author{
Ahmed Al Shebli \\ Abu Dhabi Police, \\ 253 Abu Dhabi, \\ United Arab Emirates \\ Email: axshb@hotmail.com
}

\section{Subashini Suresh}

Faculty of Science and Engineering,

University of Wolverhampton,

Wolverhampton WV1 1LY, UK

Email: S.Subashini@wlv.ac.uk

\begin{abstract}
Public sector organisations are being encouraged to embed sustainably strategies, to reduce their environmental footprint and improve social responsibility. A critical review of literature indicate that there is no empirical research reported on the key drivers for implementing sustainability initiatives in Abu Dhabi public sector organisations, which is the core objective of this paper. Given the relatively new and unexplored nature of the research problem, the qualitative research methodology was adopted. In total, 60 semistructured interviews were conducted to collect data, which was then analysed using content analysis for inference and conclusion. The data analysis revealed five key drivers that have fuelled the need for implementing sustainability initiatives. A complex mix of political, economic, social and environmental forces drives the Abu Dhabi public sector organisations to embed sustainability initiatives. Therefore, before organisations imbed sustainability initiatives they need to understand and recognise key drivers, which are pushing them towards implementation in order for them to be competitive.
\end{abstract}

Keywords: cost reduction; environmental sustainability; leadership commitment; reputation and sustainability initiatives.

Reference to this paper should be made as follows: Renukappa, S., Al Shebli, A. and Suresh, S. (201X) 'Drivers for embedding sustainability strategies within the Abu Dhabi public sector organisation: an empirical study', Middle East J. Management, Vol. XX, No. YY, pp.ZZZ-ZZZ. 
Biographical notes: Suresh Renukappa currently serves as a Senior Lecturer in the Faculty of Science and Engineering at the University of Wolverhampton. $\mathrm{He}$ holds a $\mathrm{PhD}$ in managing change and knowledge associated with sustainability initiatives for improved competitiveness. He has over 20 years of research, consultancy, project management and teaching experience in a wide range of business and management areas across industrial sectors in both developed and emerging economies. His research interests cover, but not limited to, sustainability strategies for competitive advantage; carbon reduction strategies; corporate social responsibility; leading change towards sustainability; knowledge management; public private partnerships; cloud computing; infrastructure asset management; and sustainable infrastructure investment and development. He has successfully executed more than 30 large projects and authored over 80 papers which have been published in journals, book chapters and conference proceedings.

Lt. Col. Ahmed Al Shebli has been an Officer in Abu Dhabi Police GHQ for the past 20 years. He is the acting Head of the Transport and Workshop Administration Department. He heads and participates in few committees within the GHQ. Over the past years, Ahmed led and executed a number of projects in relation to green applications and sustainable transportation in $\mathrm{Abu}$ Dhabi Police. Ahmed graduated from the UAE University with a Bachelor in Business Administration before earning his Master in Public Administration from Zayed University. Ahmed completed his $\mathrm{PhD}$ from the University of Wolverhampton in Sustainable Strategic Management.

Subashini Suresh has over 19 years of experience in research, teaching and practice in the area of Project Management and has worked in the area of Architecture, Engineering and Construction (AEC) sector in UK, USA, UAE, Nigeria, Ghana, Italy, Netherlands and India. Currently, she is a Reader of Construction Project Management at the School of Architecture and Built Environment, University of Wolverhampton. She holds a PhD in knowledge management. She received Rewarding Excellence Award for Innovation in Teaching and also for Blended Learning Tutor. She has published over 100 academic publications, which include 24 journal papers, 89 conference papers, four articles, seven book chapters, 12 reports and three books. Her key areas of interest are as follows: construction project management, knowledge management, building information modelling, health and safety, sustainability/green construction, emerging technologies, quality management, leadership in change management initiatives, organisational competitiveness, business process improvement, lean construction and Six Sigma leadership.

\section{Introduction}

Brundtland (1987) defined sustainable development or sustainability "as a development that meets present needs without compromising the ability of future generations to meet their own needs." Looking at each element separately, 'sustainability' means the capacity for an activity to be carried on indefinitely into the future, given the amount and type of resources available, whereas 'development' implies that society will change or grow in the same way. Hence, 'sustainability' suggests change and improvement that is compatible with environmental, social and other limits, both now and in the long-term future (Gray and Wiedemann, 1999).

Today, many public and private sector organisations can succeed only if they are genuinely 'value-led' and adopt a holistic rather than a silo approach to social, economic 
and environmental sustainability issues (Renukappa et al., 2016). However, the significant challenge of trying to simultaneously manage social, environmental and financial performance is one of the most critical challenges for many organisations. As noted by Drucker (2002), 'every single pressing social and global issue of our time is a business opportunity'. The above statement clearly conveys that organisations that successfully embrace the sustainability agenda and integrate it into their daily business operations will thrive. While sustainability is becoming acknowledged as a business imperative, there is little cohesive guidance as to either how managers and leaders can identify the best focus for sustainability practices in their businesses or how they can best embed them. Or indeed, how they can identify what it really means for them as unique organisations.

Porter and Kramer (2011) noted that organisations continue to view value creation narrowly, optimising short-term financial performance in a bubble while missing the most important customer needs and ignoring the broader influences that determine their longer-term success. For instance, the 2010 United Nations Global Compact - Accenture (2010) CEO study found that $93 \%$ of CEOs believe sustainability will be critical to the future success of their companies. A critical mass of business leaders, $80 \%$, believe a tipping point will be reached within the next 15 years where sustainability is embedded in the core business and strategies of most companies, and 54\% believe this tipping point could be reached within the next 10 years. Further evidence for this increased awareness is supplied by a recent Accenture global survey (2013) that revealed that $63 \%$ of CEOs expect sustainability to transform their industry within 5 years and $76 \%$ believe that embedding sustainability strategy into core business will drive revenue growth and new opportunities. Although many companies recognise the value of a sustainability strategy, most have not yet incorporated sustainability issues into their overall business strategy.

A research study by Kay (2004) on several public sector organisations suggests that though the resource-based view and triple bottom line approaches are central to the notion of competitive advantage in private firms, they only apply to public sector organisations where competition exists. This is mainly because public firms are funded by the government for public service and frequently do not need to compete with other organisations when offering a similar set of services to the public (Prajogo et al., 2012).

Many public sector organisations are occupied with the implementation of sustainability-related change initiatives. Underlying these changes is a managerial logic which implies that public sector organisations should be more based on business-like values, rather than bureaucratic principals (Wise, 2000). These changes are aimed at making public sector organisations more efficient, cost-effective and community oriented (Kickert, 2010).

The question still arises as to how and why public sector leaders can practically embrace sustainability-related changes and embed them within their organisations. While there is a substantial body of literature on technical issues of sustainability, notably resource and carbon management, and metrics to measure change, there has been considerably less research into the actual practices and integration of sustainability thinking into models and policies for public sector organisations.

To improve sustainability performance, executives have recognised that it is necessary to better understand the drivers of both costs and revenues and the actions that they can take to affect them. However, the identification and measurement of social and environmental strategies are particularly difficult as they are usually linked to long-term time horizons, a high level of uncertainty, and impacts that are often difficult to quantify 
(Epstein, 2008). Therefore, it is crucial to understand the reasons why corporate decisionmakers adopt sustainability initiatives. There is, however, no empirical research on the key drivers that have fuelled the need for implementing sustainability initiatives in the Abu Dhabi public sector organisations, which is the raison d'être of this paper.

Deloitte (2011) noted that understanding the drivers for implementing sustainability initiatives is critical for four reasons: it could (a) help business leaders to identify the resulting sustainability-related drivers in their industry and organisation; (b) act as a much-needed catalyst for stimulating internal discussion and debate about sustainability threats and opportunities in the market and society; (c) assist decision-makers to develop sustainability strategy based on the drivers and (d) expose the mechanisms that foster sustainable organisations, allowing managers and decision-makers to determine the relative efficacy of actions, market measures and voluntary measures.

For the purposes of this research, sustainability initiatives are defined as 'key practices undertaken by an organisation to support environmental, social and economic causes and to fulfil organisation's commitments to sustainability'. Causes most often supported through these initiatives are those that contribute to community health (e.g. HIV/AIDS prevention), safety (e.g. crime prevention), education (e.g. job training), employment (e.g. hiring practices), the environment (e.g. waste recycling), reducing natural resources (e.g. reducing energy consumption) and reducing carbon emission (e.g. minimising logistics operations).

\section{A case study description}

Given the dramatic changes at the global geo-political scene coupled with the unprecedented world financial crisis along with the rapid shift in the bargaining power of countries people have become cautious in every aspect of their life. There is a clear and present need for the Abu Dhabi public sector organisations to change in order to re-attain its strategic fit in line with the changes experienced in both the external and internal organisational environments (ADED, 2008).

If the political uncertainty of the Arab region is also taken into consideration and the fact that Abu Dhabi and the United Arab Emirates (UAE) are, as a whole, one of the few politically stable areas in the region that still enjoy growth, then the need for the Abu Dhabi public sector organisation to change in order to compensate for the surrounding challenges is compounded (ADPGHQ, 2013). Specifically for the public sector, the key issue is the inability to change as a result of complaisance and inertia. As a result, the organisation is falling behind and the risk of not being able to observe its mission and objectives in the future have now become a pressing matter (ADP, 2013). In addition, the changing needs of the public have been triggered from various sources some of which are the changes in government policies, sustainable development issues and strategic direction of the country's economy (ADPGHQ, 2013).

For instance, the Transportation division within the Police force caters to all of the transportation needs of the police force as well as maintenance and repairs. There are 5,600 vehicles that range in 40 different types and models. In addition to maintaining the varied police vehicles, the division is also looking after the repairs and maintenance of ambulances and rescue vehicles as well as the processing of traffic patrol cars. In line with the overall police force's strategy, the transportation division has developed its own departmental strategic plan to operationalise its activities. The key objectives of the plan 
are to provide comprehensive transport and work services; to ensure the readiness of transport and works management; to develop skills and capabilities; to ensure the effective allocation and use of finance and technology and to work in partnership and harmoniously with the other departments in the organisation (ADPGHQ, 2013).

However, the above strategic objectives, for the most part, aim at ensuring departmental technical efficiencies - and despite the emerging change spirit of the transportation division - no such objective is currently addressing sustainability-related change initiatives. Consequently, the notions of sustainability and leading change towards sustainability are presently neglected by the current departmental strategic plan.

\section{Methodology}

In order to achieve the aim of this research, a robust methodology is essential. The choice of research methodology is a crucial and difficult step in the research process (Walker, 1997). Elkington's (2001) call for more research into 'best cases' seeks to offer a contribution on how selected case study organisations fit the calls for social and environmental responsibility into their daily business operational framework. A case study approach is employed here to achieve the research aims of gaining deeper insights into public sector organisations' sustainability practices through interviews, internal reports and published data sources (Eisenhardt and Graebner, 2007; Yin, 2009). In particular, an inductive case study approach is employed to cover the contextual dimensions of sustainability issues. The case study was conducted with one of the largest public sector organisation in the Abu Dhabi, which at the time of the study was in the process of implementing a sustainable development strategy in all its operations.

Gable (1994) argued that an explorative qualitative approach is better suited to study a nascent research field and gain valuable initial insights, rather than large-scale surveys. Insights from initial expert interviews also make a strong case against large-scale quantitative surveys, due to aversion in responding to questionnaire surveys, and a high tendency to give socially desirable responses, thereby threatening the validity of responses (Collis and Hussey, 2003). Qualitative research is exploratory in nature working towards building foundations in a particular field of study by seeking understanding (Tetnowski and Damico, 1999), whereas quantitative research seeks to measure something.

According to Bryman and Bell (2007), semi-structured interviews provide some flexibility and it is one of the ways to obtain a 'realistic' picture of an individual's view. Therefore, data were collected through semi-structured interviews, and each interviewee was encouraged to express the sustainability issues that they thought were crucial in the sustainability policy process. They were asked to represent the organisation view on most matters although it was recognised that their level of seniority often meant that their own views were fundamental to the organisation view. A purposive sampling technique was used in order to achieve representativeness. A purposive sampling technique involves drawing samples that are both easily accessible and willing to participate in a study. Purposive sampling techniques are primarily used in qualitative studies and may be defined as selecting units (e.g. individuals) based on specific purposes associated with answering a research study's questions. In this study, 60 interviews were conducted with individuals whose activities were considered to be influential in the sustainable development policy formulation process. The sample included directors, deputy directors 
and managers responsible for environmental, social and economic sustainability initiatives in their respective departments of the case study organisation. The interviews lasted between 60 and $90 \mathrm{~min}$. The format of these interviews was face-to-face, and the transcripts were recorded and supplemented with field notes as appropriate.

An important sample size issue in qualitative research involves saturation of information (Strauss and Corbin, 1998). Saturation is a term used to describe the point when no new insights or range of ideas are generated through adding more data. In this study, data were collected until no new aspects of the sustainability issues were revealed. In this study, actual saturation of data occurred before the 58 interviews. Therefore, only 60 interviews were conducted.

Qualitative approaches of data analysis advocate development of interpretative aspects and categories as close as possible to the object of the study (van Dijk, 1977). In this context, analysis of the interviews was undertaken using Content Analysis. Fraenkel and Wallen (2003) noted that content analysis is a study of textual messages of human behaviour in an indirect way. This helps researchers generalise findings, predict the future, understand attitudes, values and cultural patterns of an organisation or an industry or a country.

In the study, coding of the transcribed documents involved open coding of meaning units, that is, words, phrases, sentences, paragraphs, which essentially involved labelling concepts. The emerging concepts were mapped into themes. Threats to validity were minimised through triangulation of data collection methods (interviews, internal and external documents) and verification of the initial thematic codes by participants, where they judged the accuracy of data collected, though not its conclusions. The unit of analysis adopted for this study was the 'individual employee'.

\section{The key drivers for implementing sustainability initiatives}

In the study, during face-to-face interviews, in order to capture the key drivers that have fuelled the need for implementing sustainability initiatives in the Abu Dhabi public sector organisation, a question was raised, i.e. what drivers have fuelled the need for implementing sustainability initiatives in your organisation?

Table 1 shows the key drivers that have fuelled the need for implementing sustainability initiatives as revealed by those interviewed in this study. It is evident that the most important key driver that fuelled the need for implementing sustainability initiatives is to building reputation. This is closely followed by reducing operating costs, leadership commitment, stakeholders' pressure and government legislation. Each of these key drivers is discussed in detail below.

Table 1 The key drivers that have fuelled the need for implementing sustainability initiatives

\begin{tabular}{lc}
\hline $\begin{array}{l}\text { Key driver that have fuelled the need for } \\
\text { implementing sustainability initiatives }\end{array}$ & $\begin{array}{c}\text { Total number of interviewees } \\
\text { cited }(N=60)\end{array}$ \\
\hline Reputation building & $56(93 \%)$ \\
Reducing operating costs & $54(90 \%)$ \\
Leadership commitment & $48(80 \%)$ \\
Stakeholders' requirement & $45(75 \%)$ \\
Government legislation & $40(67 \%)$ \\
\hline
\end{tabular}




\subsection{Reputation building}

In this study, $93 \%$ (56 of 60 ) of interviewees noted that reputation enhancement is a key driver for implementing sustainable practices in their organisation. As authors such as Roarty (1997) and Rodriguez-Melo and Mansouri (2011) have indicated society is becoming increasingly aware of environmental and social issues; hence, it would be advantageous to utilise sustainable initiatives in order to improve the organisation's reputation. This is made even more prevalent when reputation, brand and knowledge are considered the principle assets of a company (Kay, 2004). For instance, one of the interviewees noted that:

\footnotetext{
"We have implemented various sustainability initiatives in our organization. The very purpose of these initiatives is to enhance our reputation compared to other police forces across the world."
}

Analysis of the above statement reflects that reputation is crucial towards focusing on a developing the reputation by focusing on environmental, social and economic responsibility issues. As Fombrun and Van Reil (2003) and Al-Jenaibi (2015) point out reputation contributes to organisational stability, performance and employee loyalty, and to ease recruitment and decrease transaction costs, all of which are particularly attractive to police service organisations as they are struggling with financial and political pressures. In addition, according to Luoma-aho (2007) and Junaid and Hussain (2016), reputation has only recently been understood by organisations and still remains a much under used resource. Namely, strong reputation results from consistent information signals overtime, which constituents believe, share and trust.

Furthermore, excellent reputations require constant cultivation. Public funds are often scarce and the cultivation of reputation is rarely at the top of agenda. Indeed, the target level of reputation needs to be realistic. In other words, reputation has to be high enough for police service organisations to be trusted and taken seriously, but neutral or even low enough to acquire the necessary operating distance necessary especially in times of crisis. Reputation refers to the general image of police service organisations amongst the stakeholders enabling collaboration, leading to trust and other benefits. Yet, reputation should not be seen as an assessment of performance against expectations.

\subsection{Reducing operating costs}

Cost reduction is a key driver for implementing sustainable initiatives as in the UK, police forces are facing budget cuts and predicted increase in energy prices (Cambridgeshire Constabulary, 2011). In the study, overwhelmingly 90\% (54 of 60) interviewees asserted that this is a very important driver for implementing sustainability initiatives and was the most important driver out of all those identified. According to Accenture (2013), increased energy and water cost and growing awareness about climate change have pushed 'sustainability issues' into organisational boardrooms. Most organisations can make significant energy saving by making changes that cost little or nothing to implement. For instance, the UK carbon trust estimates that most organisations in the service sector can cut their energy bill by $20-30 \%$ while those in industry can make saving from $5 \%$ to $10 \%$. Therefore, encouraging employee to change behaviour can lead to big savings. 
The study results revelled that $75 \%$ (45 of 60 ) interviewees noted that their organisation is having more energy and water consumption. Therefore, their organisation wants to adopt the 'sustainable' policies in order to reduce energy and water consumption. For instance, one of the interviewees noted that a key driver for their organisation is:

"Majority of the time it is a cost based decision if they are not going to see any
benefit from using sustainable measures then it is unlikely they will go ahead."

The view of the interviewee clearly suggests that organisations are implementing various cost saving initiatives. This is indicated by Bansal (2005) where it is stated that sustainable initiatives are adopted in order to reduce costs. Cost reduction is obtained through a number of methods as detailed by the interviewees where cost was looking to be saved from materials, energy usage and waste management. Various sustainability initiatives such as eco-efficiency form basic components of sustainability (Savitz and Weber, 2006) where efficiency of resources and services are obtained through the decrease in the organisation's operating costs. The emphasis of resource management also matches alongside Zabihi et al. (2012) stating resource efficiency and energy efficiency among the key principles of sustainable practices. However, $10 \%$ (5 of 60 ) interviewees do not think that there is a business case for sustainability initiatives. These interviewees argued that the cost for implementing sustainability initiatives is more than return. However, Renukappa et al. (2014) noted that the continuing rise in price of fossil fuels and the need to reduce carbon emissions will indefinitely face organisations with threats, leading to the need to implementing sustainability initiatives.

In summary, organisations that see sustainability as opportunities to place themselves into a situation where it can reap benefits in the terms of cost saving will no doubt increase their competitiveness (Renukappa et al., 2014). If organisations visualise to be cost leaders, they will aim to be the low-cost producer. Hence, if an organisation can become and sustain cost leadership, then that organisation will reach higher performance in the industry and would reap the benefits of competitive advantage over others. In spite of this, it is important to note that organisations aiming to be cost leaders cannot ignore differentiation and needs to achieve proximity in all bases relative to competitors to be able to performance higher than the average rate (Porter, 1985).

\subsection{Leadership commitment}

Leadership commitment is indefinitely a key driver in addressing sustainability concerns as it involves the need for participation by high level members of police service organisations, for example Commissioners or Chief Constables. This is required for the implementation of sustainability practices to ensure they are in line with organisational goals and revising practices or policies if needed (Renukappa et al., 2014). Hence, commitment is essential in order for all police organisations to function efficiently.

In the study, $80 \%$ ( 48 of 60 ) interviewees noted that leadership commitment was a considerable driver for implementing sustainability initiatives in their organisation. This driver is related towards socially proactive organisations where management support is given towards environmental and social issues. Statements related to this driver are seen as management commitments being adhered to by members of the organisation.

Leadership commitment is crucial towards addressing sustainable issues due to top management having the ability in persuading organisations (Doppelt, 2009). The 
commitments undertaken are seen as the responsible course of action to by managers given their roles. Some of these commitments may not emphasise any overt perspective to allow for sustainability initiatives to be utilised providing an advantage but rather due to a responsibility felt by managers. This is illustrated by a quote obtained from an estate manager:

"I have that sort of personal ambition but being in estates, frequently organisation initiatives and that's recycling, bins and all that. We are driven by our peers within estate management who say we need to do that, we need to do this. Furthermore, senior management's inclination towards addressing social issues has also motivated to address sustainability issues and ensure that there is a job creation in the market."

The above quote demonstrates a sense of personal responsibility from the interviewee along with an overriding responsibility among his peers encouraging sustainable initiatives to take place. What this allows is a greater alignment with the organisation's business environment in order to maintain a dynamic balance as detailed by Porter (1991).

Managerial commitments are expected to not just altruistic but also the outcomes of these commitments could serve to help the company achieve goals as shown in the following quote from an interview:

"Also attracting the right staff to the business, people want to work for a sustainable business that shows this in different ways."

Some employees prefer to work in a sustainability conscious organisation instead of a non-responsible firm through screening (Brekke and Nyborg, 2008). This would be done using their profile as a screening device in order to obtain more productive employees in line with the principles of sustainable development (Brekke and Nyborg, 2008). This indicates how sustainability initiatives have been implemented by management in order to develop a like-minded culture within the organisation trickling down from the management.

Conversely, 20\% (12 of 60) interviewees noted that leadership commitment was not important driver. This suggests that interviewees may miss-interpret the importance of leadership commitment as this can affect the reputation, shareholder values, benefit to social groups and the enhancement of the physical environment. In summary, for the implementation of sustainability initiatives or changes in strategy it can be foreseen leadership commitment is needed. Leadership commitments are necessary for the transition of efficient systems focused on resource management and cost reduction alongside leadership, culture, innovation and resources.

\subsection{Stakeholder's requirements}

In the study, $75 \%$ ( 45 of 60 ) interviewees pointed out that stakeholder's pressure is a very important driver for implementing sustainability initiatives within their organisation. Stakeholders are individuals, groups or organisations that have an interest in what a police service has done, is currently doing, or might do. Stakeholder requirements/pressure is a key driver as stakeholders are able to influence what a police service does depending on their social or political power. In policing, the community is one important stakeholder. Other stakeholders include their employees, their union, 
suppliers and potentially those outside of the local community with an interest in a police service's actions. For instance, one of the interviewees noted that:

"Our organisation vision, mission, values and strategic priorities related to sustainability drive by various stakeholders pressures. For example, one of our strategic priorities keeping Abu Dhabi emirate secure, safe and at the same time sustainable. This is the priority of the UAE Government. Therefore, in our organisation we are working and practising the police work keeping in mind protecting environment and let it clean and free from waste."

The above statement acknowledges that organisations are under pressure to react to targets set by stakeholders in order to comply with their needs and interests. However, $25 \%$ (15 of 60 ) stated that stakeholders' pressure is fairly important driver. This may be due to the fact that these individuals have a lack of knowledge of the pressure of stakeholders' upon their organisation or the fact that different organisations/departments have different objectives.

In summary, as organisations have to react to stakeholders pressures, this will bring a greater sense of conflict between organisational objectives. It will be difficult for organisations to prioritise the interests of their stakeholders. In today's world, organisations of all types are well aware of the importance of understanding and catering to stakeholders; therefore, an organisation needs to satisfy and impress stakeholders.

\subsection{Government legislation}

The UAE government has recognised alongside the international community sustainable development needs to be become a key factor in order to address key problems such as climate change. The emphasis and attention towards sustainability is made clear in the following statement, "Our long term economic growth relies on protecting and enhancing the environmental resources that underpin it, and paying due regard to social needs. As part of our commitment to enhance wellbeing" (UAE, 2015).

In this study, 67\% (44 of the 60) of the interviewees stated that another key driver for implementing sustainability initiatives was due to government regulation. The UAE Government-funded programmes and projects are generally the vehicles for climate change response rather than specific legislation. At Federal level, the UAE is developing two key frameworks for climate change mitigation: the Green Growth Strategy and the Federal Energy Policy. The former seeks to decouple economic growth through greenhouse gases and other environmental impacts through policies and targets across seven key sectors (Grantham Research Institute, 2015).

In the UAE, there has recently been a consensus to legislate for energy efficiency, which suggests the government has realised the benefits of energy efficiency. Indeed, new building energy codes known as the green building codes are the first step towards developing sustainable policies in the UAE. These new codes conform to the most demanding global standards, which were developed in line with the International Code Council (ICC) whom are responsible for advising US regulators. In addition to this, UAE government put in place the Estidama program and the Pearls green building rating system, which is integrated with the building code. This means that it is enforceable and along with the launch of the Emirates Green Buildings council is an important step towards low carbon emission buildings in the UAE (Radhi, 2010). For instance, one of the interviewees noted that: 
"So that's what's going to happen and we have to hope what we do would fall in line with that green regulatory approach. If they don't have the regulations of course the industry won't get there, the regulations would be necessary."

The aforementioned view of the interviewee clearly suggests that Government regulation/legislation is also an important key driver for implementing sustainability initiatives. The above quote highlights inevitability of sustainability demonstrating the success of the government's attempts to mainstream sustainability. The government's use of legislation has been effective as one of the quickest and certain methods of implementing change by ensuring an organisation remains competitive it must remain up to date with existing and emerging legislation (Waddell, 2008). Many organisations are regulatory compliance by voluntarily developing and certifying their environmental management systems under ISO 14001 guidelines. To sum up, it is clear that government mandatory legislation plays an important part in driving police service organisations towards implementing sustainable practices.

\section{Conclusion}

In an increasingly resource-constrained world, sustainability will continue to be a focus for many public sector organisations, as they consider society's long-term prosperity (Lacy et al., 2010). Sustainability is about building a society in which a proper balance is created between economic, social and environmental objectives. Sustainability is all about integrated thinking - opportunities, interconnections, risks, solutions, impacts. It improves efficiency, productivity and value. It supports and enhances the governance systems most organisations already have in place. The organisations that have used it to strengthen their businesses have aligned their values, mission and goals with sustainability.

Before starting to embed sustainability initiatives, executives have to recognise and better understand the drivers of both costs and value for money and the actions that they can take to affect them. This paper has explored the key drivers that have fuelled the need for implementing sustainability initiatives in the Abu Dhabi public sector organisations. As revealed by the study, the five key drivers that have fuelled the need for implementing sustainability initiatives include building reputation, reducing operating costs, leadership commitment, stakeholders' pressure and Government legislation. It should be noted that for some organisations, key drivers may be all of these drivers or combination of some of the drivers. This paper provides a richer insight into the understanding and awareness of the key drivers for implementing sustainability initiatives. This could assist decisionmakers to develop and deploy sustainability strategy based on key drivers.

This paper concludes the concept of sustainability is multifaceted and diverse. A complex mix of political, economic, social and environmental forces drives the Abu Dhabi public sector organisation to implement sustainability initiatives. Before organisations imbed sustainability initiatives, they need to understand and recognise key drivers, which are pushing them towards implementation. Therefore, understanding the drivers for implementing sustainability initiatives is important to enhance their competitiveness. Although the overall outlook of sustainability initiatives efforts from the Abu Dhabi public sector organisation looks quite promising at present, it is essential to continue the process of monitoring and identifying new emerging sustainability issues and solutions. 
The practical implications of this research are to move towards a more advanced stage of sustainability integration and improve the decision-making process, the drivers of sustainability and the linkages between them must be analysed. A clear set of impacts that are caused by organisational activities and an understanding of these impacts on different stakeholders will also aid managerial decisions.

Given that the research reported in this paper is largely exploratory by nature, the results presented here are only tentative and of limited value for the purpose of generalisability. Furthermore, findings of this paper are limited to the Abu Dhabi context only, as such, the level of generalisability outside this context may be very limited. Therefore, additional research is required to explore the complex mix of key drivers for implementing sustainability initiatives in other countries, particularly, in emerging economies, since that is where the greatest potential for future unsustainable growth exists. This should lead to a generation of benchmark data and identification of best practices in addressing global sustainability issues. The critical tensions and benefits, which derive, particularly, from the triple bottom line paradigm that can influence knowledge embeddedness within organisational settings, are also worthy of investigation.

\section{References}

Accenture (2013) The UN Global Compact-Accenture CEO Study on Sustainability 2013, Accenture Consulting, New York.

ADED (2008) The Abu Dhabi Economic Vision 2030, Abu Dhabi Council for Economic Development, Abu Dhabi Government, Abu Dhabi.

ADP (2013) SWOT Analysis Report, Abu Dhabi Government, Abu Dhabi.

ADPGHQ (2013) PESTEL Analysis 2013-2018, Produced by the ABPGHQ Strategy Team, Abu Dhabi.

Al-Jenaibi, B. (2015) 'Current issues about public relations professionals: challenges and potentials of PR in UAE organisations', Middle East Journal of Management, Vol. 2, No. 4, pp.330-351.

Bansal, P. (2005) 'Evolving sustainably: a longitudinal study of corporate sustainable development', Strategic Management Journal, Vol. 26, No. 3, pp.197-218.

Brekke, K.A. and Nyborg, K. (2008) 'Attracting responsible employees: Green production as labor market screening', Resource and Energy Economics, Vol. 30, No. 4, pp.509-526.

Brundtland, G. (1987) Our Common Future: The World Commission on Environment and Development, Oxford University Press, Oxford.

Bryman, A. and Bell, E. (2007) Business Research Methods, Oxford University Press, Oxford.

Cambridgeshire Constabulary (2011) Cambridgeshire Constabulary Carbon Management Programme (CMP), Cambridgeshire Constabulary, Cambridgeshire.

Collis, J. and Hussey, R. (2003) Business Research: A Practical Guide for Undergraduate and Postgraduate Students, Palgrave Macmillan, Basingstoke.

Deloitte (2011) Sustainability in Business Today: A Cross-Industry View, Deloitte Consulting LLP, London.

Doppelt, B. (2009) Leading Change Toward Sustainability: A Change-Management Guide for Business, Government and Civil Society, Greenleaf-Publishing, Sheffield.

Drucker, P. (2002) Managing in the Next Society, HarperCollins, New York.

Eisenhardt K. and Graebner, M. (2007) 'Theory building from cases: opportunities and challenges', Academy of Management Journal, Vol. 50, No. 1, pp.25-32.

Elkington, J. (2001) The Chrysalis Economy: How Citizen CEOs and Corporations Can Fuse Values and Value Creation, Capstone Publishing, Oxford. 
Epstein, M.J. (2008) Making Sustainability Work: Best Practices in Managing and Measuring Corporate Social, Environmental and Economic Impacts, Greenleaf Publishing, Sheffield.

Fombrun, C. and van Riel, C. (2003) The Reputational Landscape, in Revealing the Corporation: Perspectives on Identity, Image, Reputation, Corporate Branding, and Corporate-Level Marketing, Balmer, J. and Greyser, S. (Eds.): Routledge, London.

Fraenkel, J.R. and Wallen, N.E. (2003) How to Design and Evaluate Research in Education, McGraw-Hill Companies, Inc., New York.

Gable, G. (1994) 'Integrating case study and survey research methods: an example in information systems', European Journal of Information Systems, Vol. 3, No. 2, pp.112-126.

Grantham Research Institute (2015) Climate Change Legislation in the United Arab Emirates, An Excerpt from the 2015 Global Climate Legislation Study, A Review of Climate Change Legislation in 99 Countries, The London School of Economics and Political Science, London.

Gray, P.C.R. and Wiedemann, P.M. (1999) 'Risk management and sustainable development: Mutual lessons from approaches to the use of indicators', Journal of Risk Research, Vol. 2, No. 3, pp.201-218.

Junaid, M. and Hussain, K. (2016) 'Impact of brand personality, perceived quality and perceived value on brand love; moderating role of emotional stability', Middle East Journal of Management, Vol. 3, No. 4, pp.278-293.

Kay, J. (2004) The Truth About Markets: Why Some Nations Are Rich but Most Remain Poor, Penguin, London.

Kickert, W.J.M. (2010) 'Managing emergent and complex change: The case of the Dutch agencification', International Review of Administrative Sciences, Vol. 76, No. 3, pp.489-515.

Lacy, P., Cooper, T., Hayward, R. and Neuberger, L. (2010) New Era of Sustainability: UN Global Compact - Accenture CEO Study 2010, Accenture, London.

Luoma-aho, V. (2007) 'Neutral reputation and public sector organizations', Corporate Reputation Review, Vol. 10, pp.124-143.

Porter, M.E. (1985) Competitive Advantage, Free Press, New York.

Porter, M.E. (1991) 'Towards a dynamic theory of strategy', Strategic Management Journal, Vol. 12, pp.95-117.

Porter, M. and Kramer, M. (2011) 'Creating shared value', Harvard Business Review, Vol. 1-2, pp.62-77.

Prajogo, D., Chowdhury, M., Yeung, A.C.L. and Cheng, T.C.E. (2012) 'The relationship between supplier management and firm's operational performance: a multi-dimensional perspective', International Journal of Production Economics, Vol. 136, No. 1, pp.123-130.

Radhi, H. (2010) On the Effect of Global Warming and the UAE Built Environment, Harris, S.A. (Ed.), Global Warming Society, InTech Europe, Rijeka, Croatia, pp.272-978.

Renukappa, S., Akintoye, A., Egbu, C. and Suresh, S. (2016) 'Sustainable procurement strategies for competitive advantage: an empirical study', Proceedings of the Institution of Civil Engineers - Management, Procurement and Law, Vol. 169, No. 1, pp.17-25.

Renukappa, S., Egbu, C., Akintoye, A. and Suresh, S. (2014) 'Drivers for embedding sustainability initiatives within selected UK industrial sectors', The Journal of International Real Estate and Construction Studies, Vol. 1, No. 3, pp.51-72.

Roarty, M. (1997) 'Greening business in a market economy', European Business Review, Vol. 97, No. 5, pp.244-254.

Rodriguez-Melo, A. and Mansouri, S.A. (2011) 'Stakeholder engagement: defining strategic advantage for sustainable construction', Business Strategy and the Environment, Vol. 20, pp.539-552

Savitz, A.W. and Weber, K. (2006) The Triple Bottom Line, Jossey-Bass, San Francisco, CA.

Strauss, A. and Corbin, J. (1998) Basic of Qualitative Research: Techniques and Procedures for Developing Grounded Theory, Sage, Thousand Oaks, CA. 
Tetnowski, J.A. and Damico, J.S. (2001) 'A demonstration of the advantages of qualitative methodologies in stuttering research', Journal of Fluency Disorders, Vol. 26, pp.17-42.

UAE (2015) UAE State of Energy Report 2015, Ministry of Energy, Abu Dhabi, UAE.

United Nations Global Compact - Accenture CEO (2010) A New Era of Sustainability, UN Global Compact-Accenture CEO Study, New York.

Van Dijk, T.A. (1977) Text and Context: Explorations in the Semantics and Pragmatics of Discourse, Longman Publisher, London.

Waddell, H. (2008) 'Sustainable construction and UK legislation and policy', ICE, Management, Procurement and Law, Vol. 161, No. MP3, pp.127-132.

Walker, D.H.T. (1997) 'Choosing an appropriate research methodology', Construction Management and Economics, Vol. 24, pp.509-519.

Wise, L.R. (2000) 'Public management reform: Competing drivers of change', Public Administration Review, Vol. 62, No. 5, pp.555-567.

Yin, R.K. (2009) Case Study Research: Design and Methods, Sage, Thousand Oaks, CA.

Zabihi, H., Habib, F. and Mirsaeedie, L. (2012) 'Sustainability in building and construction: revising definitions and concepts', International Journal of Emerging Sciences, Vol. 2, No. 4 , pp.570-578. 